\title{
Risk of Complication and Revision Total Hip Arthroplasty Among Medicare Patients with Different Bearing Surfaces
}

\author{
Kevin J. Bozic MD, MBA, Kevin Ong PhD, Edmund Lau MS, \\ Steven M. Kurtz PhD, Thomas P. Vail MD, Harry E. Rubash MD, \\ Daniel J. Berry MD
}

Published online: 18 February 2010

(c) The Author(s) 2010. This article is published with open access at Springerlink.com

\begin{abstract}
Background To address the long-term problems of bearing surface wear and osteolysis associated with conventional metal-polyethylene (M-PE) total hip arthroplasty (THA), metal-metal (M-M), and ceramic-ceramic (C-C) bearings have been introduced. These bearing surfaces are associated with unique risks and benefits and higher costs. However the relative risks of these three bearings in an older population is unknown. Questions/purposes We compared the short-term risk of complication and revision THA among Medicare patients having a primary THA with metal-polyethylene (M-PE), metal-metal (M-M), and ceramic-ceramic (C-C) bearings. Methods We used the 2005 to 2007 100\% Medicare inpatient claim files to perform a matched cohort analysis in
\end{abstract}

Each author certifies that the institution where the work was performed approved the human protocol for this investigation, that all investigations were conducted in conformity with ethical principles of research.

This work was performed at University of California, San Francisco and Exponent, Inc.

Financial support was received from the Orthopaedic Research and Education Foundation. One or more of the authors (SMK, KO, EL) are employees of Exponent, Inc. One or more of the authors (DJB, $\mathrm{TPV})$ receive consulting income and royalties from DePuy, Inc. One author (HER) receives royalties from Zimmer, Inc.

K. J. Bozic, T. P. Vail

Department of Orthopaedic Surgery, University of California,

San Francisco, CA, USA

\section{K. J. Bozic (凶)}

Philip R. Lee Institute for Health Policy Studies, University of California, 500 Parnassus, MU 320W, San Francisco, CA 94143-0728, USA

e-mail: kevin.bozic@ucsf.edu; bozick@orthosurg.ucsf.edu

K. Ong, S. M. Kurtz

Exponent, Inc, Philadelphia, PA, USA three separate cohorts of THA patients (M-PE, M-M, and $\mathrm{C}-\mathrm{C})$ who were matched by age, gender, and US census region. Multivariate Cox proportional-hazards models were constructed to compare complication and revision THA risk among cohorts, adjusting for medical comorbidities, race, socioeconomic status, and hospital factors.

Results After adjusting for patient and hospital factors, M-M bearings were associated with a higher risk of periprosthetic joint infection (hazard ratio, 3.03; confidence interval, 1.02-9.09) when compared with C-C bearings ( $0.59 \%$ versus $0.32 \%$, respectively). There were no other differences among bearing cohorts in the adjusted risk of revision THA or any other complication.

Conclusions The risk of short-term complication (including dislocation) and revision THA were similar among appropriately matched Medicare THA patients regardless of bearing surface. Hard-on-hard THA bearings are of questionable value in Medicare patients, given the higher cost associated with their use and uncertain longterm benefits in older patients.

Level of Evidence Level II, prognostic study. See Guidelines for Authors for a complete description of levels of evidence.

\author{
E. Lau \\ Exponent, Inc, Menlo Park, CA, USA \\ H. E. Rubash \\ Department of Orthopaedic Surgery, Massachusetts General \\ Hospital, Boston, MA, USA \\ D. J. Berry \\ Department of Orthopaedic Surgery, Mayo Clinic, Rochester, \\ MN, USA
}




\section{Introduction}

THA is one of the most clinically successful and costeffective healthcare interventions. Numerous investigators have reported improved function, reduced pain, and high rates of implant survivorship at up to 20 years' followup $[4,29]$. However, concerns about limitations in implant longevity related to the osteolysis associated with metalon-polyethylene (M-PE) bearing surface wear have led to innovation in tribology $[10,15,16]$ and the introduction of new THA bearing couples over the past decade. In particular, second-generation hard-on-hard bearings, including metal-on-metal (M-M) and ceramic-on-ceramic (C-C), have been introduced into the US market based on laboratory studies showing lower wear rates when compared with M-PE bearings [9, 10, 15]. Lower wear rates associated with hard-on-hard bearings are likely to have the biggest impact on revision rates in younger, more active patients, who are at higher risk for wear-related failures [3, 12, 17, 18, 27]. The long-term benefits of more costly hard-on-hard bearings are less obvious in older patients, who are at lower risk for wear-related failures. However, a potential benefit of M-M bearings is the ability to use large diameter femoral heads, which theoretically could result in a lower short-term risk of dislocation when compared with M-PE bearings. This potential benefit could be particularly advantageous in older patients who are reportedly at higher risk for THA dislocation $[5,25,28]$.

We previously evaluated the epidemiology of THA bearings in the entire United States population [7]. However, that study employed a cross-sectional study design, and due to the nature of the database used (the Nationwide Inpatient Sample), we were unable to compare longitudinal patient outcomes and differences in the risks of complication and revision THA among patients with different THA bearings [7].

The purpose of this study was to compare the short-term risk of complication and revision THA among Medicare patients having a primary THA with M-PE, M-M, and C-C THA bearings.

\section{Patients and Methods}

The 2005 to 2007 100\% Medicare inpatient claim files were used to perform a matched cohort analysis in three separate cohorts of THA patients (M-PE, M-M, C-C). Patients in each THA cohort were matched by age, gender, and US census region to the comparison or 'control' cohort, using a three to one matching ratio. M-M hip resurfacing arthroplasty procedures (which have a separate ICD-9-CM procedure code) were excluded from the analysis. Each M-M patient and C-C patient (case) were matched to three M-PE patients (control), while each C-C patient (case) was matched to three M-M patients (control). For each 'case' patient, the eligible pool of controls consisted of those patients who were within 3 years in age of the case patient and who were at least 65 years old. If more eligible controls were available than the three required per case, controls closest in age were selected first. Eligible controls were also of the same gender and resided in the same US Census region. All cases and controls had to be enrolled in both Part A and Part B of Medicare. Patients who received their Medicare health benefits through a health maintenance organization were excluded because their healthcare expenses were not submitted to the Centers for Medicare and Medicaid Services (CMS) for payment and, therefore, claims from these beneficiaries were not available from the database.

Primary THA patients were identified using International Classification of Diseases, 9th rev, Clinical Modification (ICD-9-CM) procedure code 81.51 from the inpatient claims records and grouped into three bearing cohorts based on their corresponding ICD-9-CM optional procedure modifier bearing codes $(00.74$ for M-PE, 00.75 for M-M, 00.76 for C-C). Using each patient's unique de-identified beneficiary ID, the patients were tracked longitudinally with revision THA or selected complications as end points. Revision surgery was identified using ICD-9CM procedure codes $00.70-00.73$ and 81.53 . The selected complications included deep venous thrombosis (DVT), dislocation, infection, and mechanical loosening. DVT was identified using the ICD-9-CM diagnosis codes 451.1, 451.2, 451.81, 451.9, 453.1, 453.2, 453.4, 453.8, and 453.9, while THA dislocation was identified using any occurrence of ICD-9 diagnosis codes 718.35, 835, or 996.42. Infection and mechanical loosening were identified using ICD-9 diagnosis codes 996.66 and 996.41, respectively.

An overall cohort of 36,423 THA patients with M-PE bearings were identified, along with 17,789 THA patients with M-M bearings and 2,835 THA patients with C-C bearings, from which the matched cohorts were derived. The mean age of all THA recipients included in the study was 74.5 years $(\mathrm{SD}=6.4$ years).

Multivariate Cox proportional-hazards models were constructed to compare complication and revision THA risk among cohorts, adjusting for medical comorbidities, race, socioeconomic status, and hospital factors. The Medicare buy-in status was used as an identifier of patients whose Medicare premiums and deductibles were subsidized by the state (eg, Medicaid) and were used as a proxy for the patient's socioeconomic status. To account for the health status of 
each patient, the Charlson comorbidity index was used as a measure of comorbid illness [13]. For this analysis, the Charlson index values were grouped into the following previously validated categories: 0 (none), 1 to 2 (low), 3 to 4 (moderate), and 5 or more (high) [24].

\section{Results}

Among younger Medicare patients (aged 65-69 years), M-M bearings accounted for $35 \%$ of THA bearings and $\mathrm{C}-\mathrm{C}$ bearings accounted for $8 \%$. Among older Medicare patients (older than 80 years), $69 \%$ of patients had M-PE bearings (Fig. 1). Among female patients, $67 \%$ had M-PE bearings, while $29 \%$ had M-M bearings, compared to male patients, among whom 60\% had M-PE and 35\% had M-M bearings (Fig. 2). The highest frequency of M-PE bearing surface use was in the Northeast (72\%), and the highest frequency of M-M bearing usage was in the South (37\%), while $\mathrm{C}-\mathrm{C}$ bearing usage was fairly consistent across the four US census regions (4\%-5\%) (Fig. 3).

When comparing the unadjusted risk of complication using the Kaplan-Meier method, M-M bearings showed an apparent trend toward higher overall risk of DVT (Fig. 4) and revision THA (Fig. 5) than C-C bearings. However, these differences were not present after adjusting for other covariates in these matched cohorts (Table 1). After controlling for patient and hospital factors, M-M bearings were associated with a higher risk of periprosthetic joint infection (hazard ratio, 3.03; confidence interval, 1.02-9.09) when compared with C-C bearings. There were no other differences among cohorts in the adjusted risk of revision THA or any other complication, including DVT, dislocation, or mechanical loosening (Table 1).

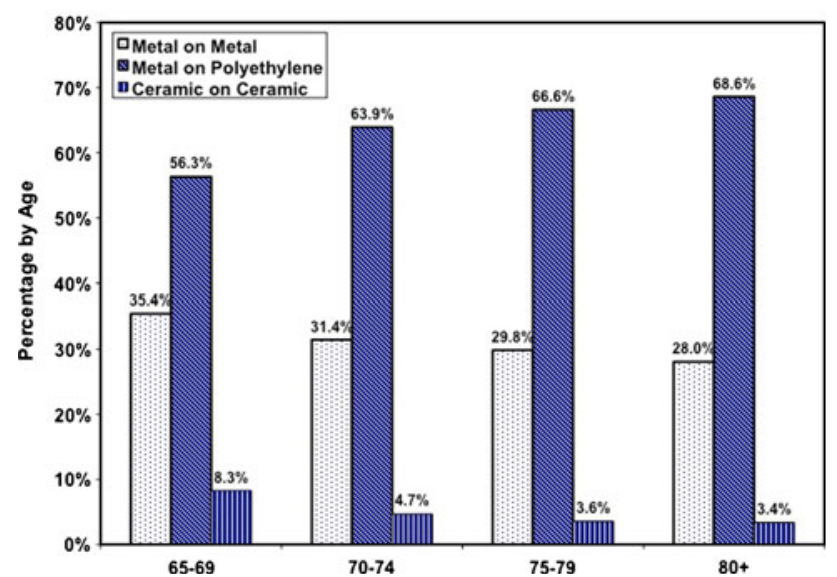

Fig. 1 The bearing surface frequency in Medicare THA patients by age is shown.

\section{Discussion}

THA has become one of the most commonly performed operations in Medicare patients, with over 160,000 primary and revision THA procedures reported in Medicare patients in 2007 [1]. Successful THA allows elderly patients who suffer from disabling hip disease to regain their function and maintain a more active, healthy lifestyle. Nevertheless, increased utilization and rising costs have led to concerns regarding the appropriateness of using 'premium', more expensive implant technologies in Medicare patients. Hardon-hard bearings are associated with lower wear rates in the laboratory setting $[15,20]$. However, wear-related failures, such as bearing surface wear, osteolysis, and mechanical loosening, may be less of a concern among Medicare patients when compared with younger, more active patients who undergo primary THA [8]. Therefore, the higher cost associated with hard-on-hard bearings may

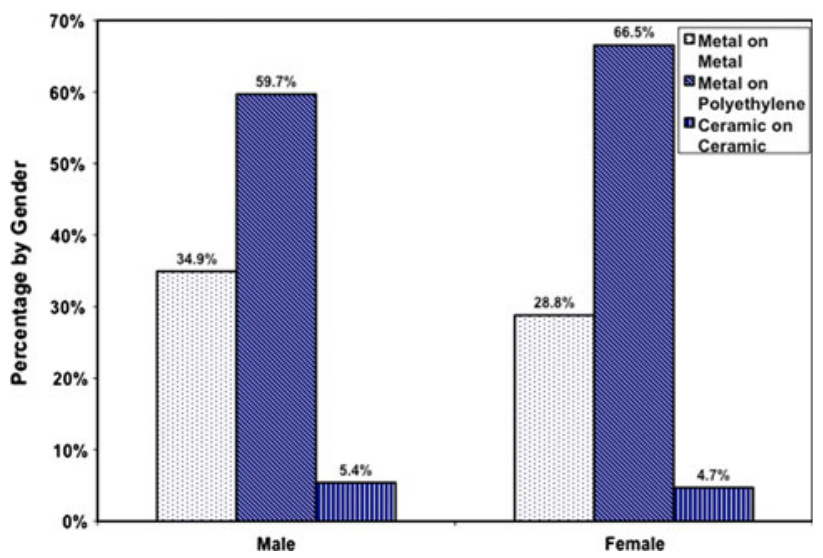

Fig. 2 The bearing surface frequency in Medicare THA patients by gender is shown.

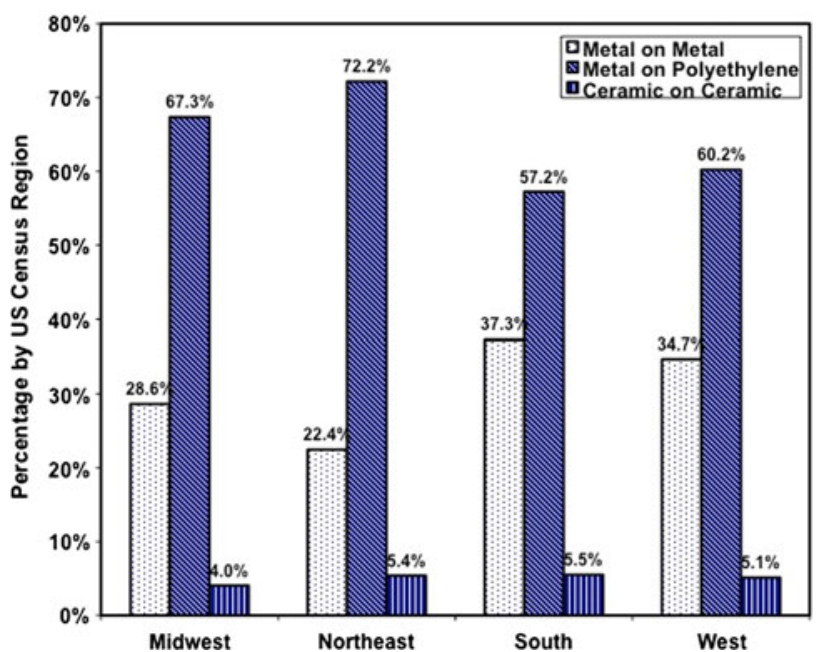

Fig. 3 The bearing surface frequency in Medicare THA patients by US census region is shown. 
Fig. 4 This graph shows trends of higher overall rates of DVT for M-M versus C-C bearings (unadjusted). $(\mathrm{T})=$ percentage of patients without the complication (DVT) at the given time points.

Fig. 5 This graph shows trends of higher overall rates of revision for M-M versus $\mathrm{C}-\mathrm{C}$ bearings (unadjusted). $(\mathrm{T})=$ percentage of patients without the complication (revision) at the given time points.
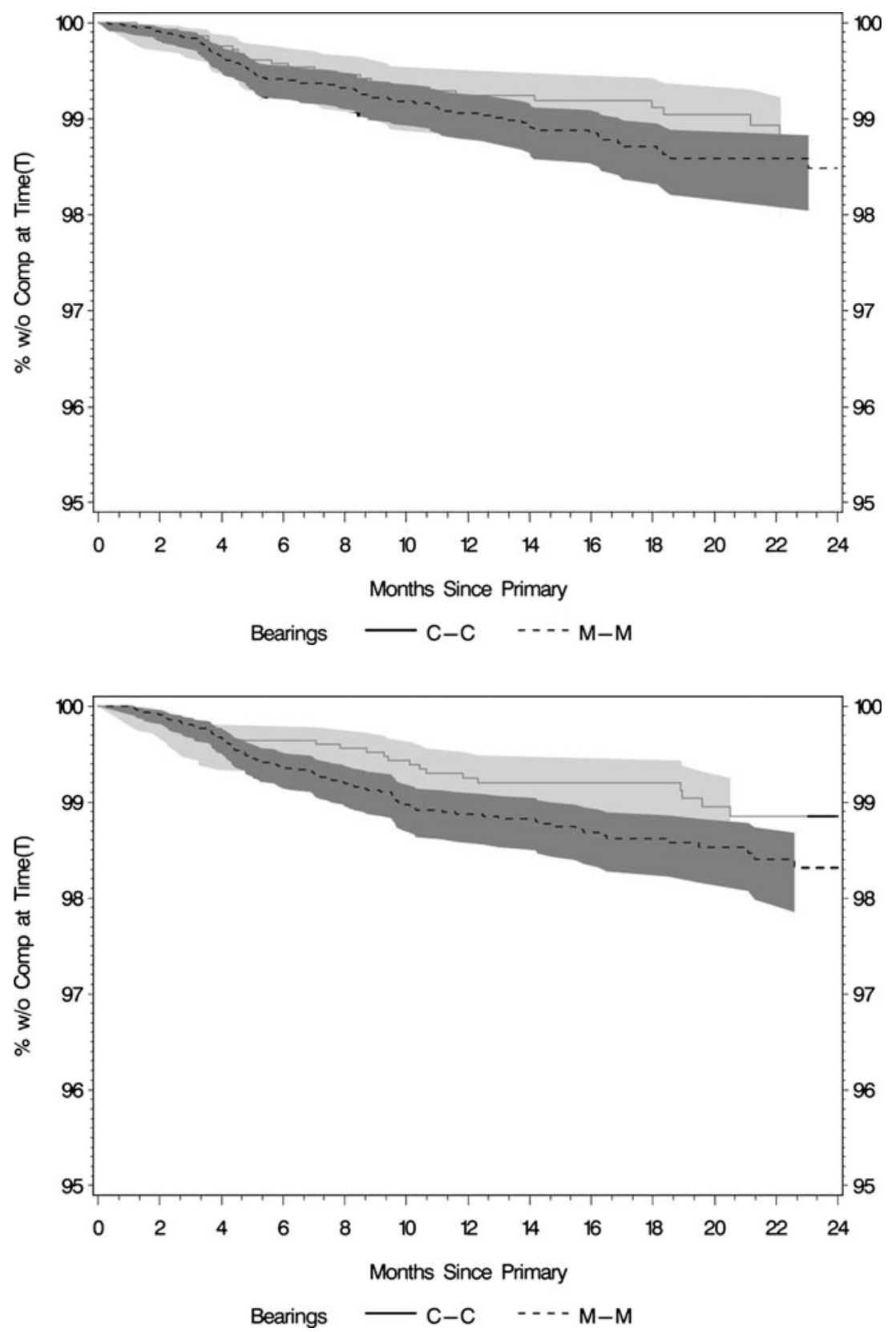

not be justifiable in terms of improved patient outcomes and lower reoperation rates in Medicare patients, unless they are associated with fewer short-term complications, such as dislocation. One example of a potential short-term benefit of M-M bearings that is often cited is the ability to use large diameter femoral heads, which theoretically could result in a lower risk of dislocation when compared with M-PE bearings. We therefore compared the short-term risks of complication and revision THA among Medicare patients having a primary THA with M-PE, M-M, and C-C THA bearings.

Our findings are limited by the use of an administrative database, where bearing surface type is an optional modifier code that can be reported in conjunction with the primary procedure code (primary or revision total hip arthroplasty), which introduces a potential source of bias into our study. However, this limitation is somewhat mitigated by the matched cohort study design, where patients with known bearing types were matched by age, gender, and U.S. census region. Second, other variables of interest which may influence patient outcomes, including surgical approach, surgeon experience, and implant design are not accessible from administrative claims, and we were only able to evaluate complications which are captured in administrative claims data, such as DVT, dislocation, infection, mechanical loosening, and revision surgery, 


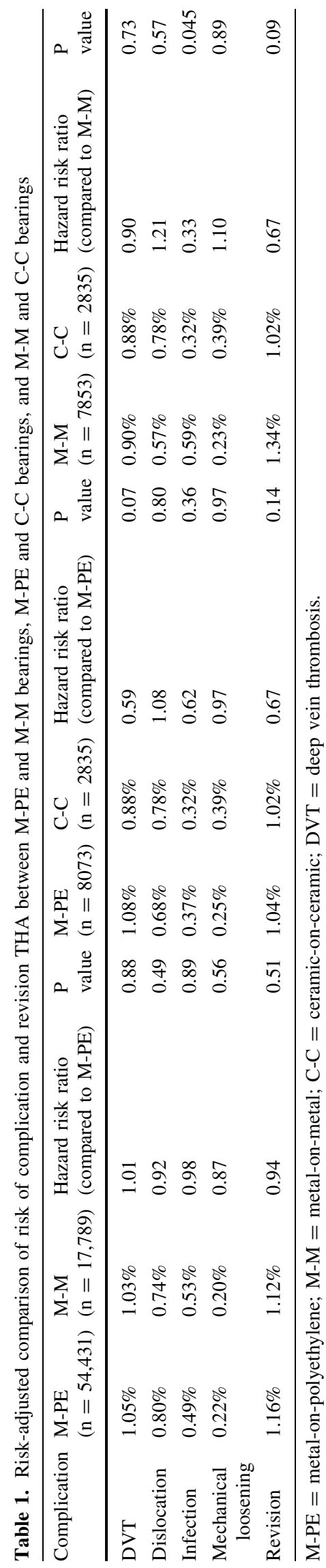

rather than pain and patient reported functional outcomes. Third, since the optional bearing surface modifier administrative codes were not introduced until October, 2005, our study was limited to outcomes and complications that occurred within two years of the index procedure. However, the rationale for our study was that presumably the reason for using alternative bearings in Medicare patients is to reduce short-term complication rates (eg, dislocation), rather than long-term complications (eg, wear/osteolysis), which are more of a concern in younger patients than in Medicare patients. Furthermore, the Australian hip registry [2] and other reports in the literature [6, 11, 19, 22, 23, 26] have raised concerns regarding higher than expected shortterm complication and revision rates in patients with hardon-hard bearings. Nevertheless, further study is necessary to evaluate differences in long-term clinical outcomes and revision rates as additional data becomes available.

We found the adjusted risk of short-term complication and revision THA among Medicare THA patients was similar, regardless of bearing surface, with the exception of patients who had M-M bearings, who had a slightly higher risk of periprosthetic joint infection than patients who had $\mathrm{C}-\mathrm{C}$ bearings. The reasons underlying the increased risk of infection for M-M bearings compared with C-C bearings, even after adjusting for medical comorbidities and hospital factors, remain unclear. It is possible that some of these patients may have been misdiagnosed as having a periprosthetic joint infection when in fact they had a local soft tissue inflammatory reaction related to the M-M articulation $[6,11]$. The findings in some patients with such reactions mimic periprosthetic joint infection, as reported previously by Mikhael et al. [22]. Although the higher risk of infection in the M-M cohort compared with the C-C cohort was significant (Hazard Ratio 3.03, CI $=1.02-$ 9.09), the clinical importance of this difference is unclear, especially given the relatively low incidence of infection ( $0.59 \%$ versus $0.32 \%$, respectively).

The relatively high incidence of M-M bearings reported in the Medicare population is somewhat surprising, given $\mathrm{M}-\mathrm{M}$ bearings are thought by some to be primarily indicated for younger, more active patients who are at higher risk for bearing surface wear and osteolysis with M-PE bearings $[14,17,20]$. However, one theoretical advantage of M-M bearings in older patients is improved stability (eg, lower risk of dislocation) due to the ability to use largerdiameter femoral heads. Our data do not demonstrate an advantage of M-M bearings in terms of lower short-term risk of dislocation when compared with either M-PE or $\mathrm{C}-\mathrm{C}$ bearings. This could be related to the increasing trend of using 32- and 36-mm heads in M-PE bearings, which may be sufficient to substantially reduce the risk for dislocation. Although the database used in this study did not include information about femoral head size, according to 
industry sources [21], the proportion of femoral heads implanted in the US sized $32 \mathrm{~mm}$ or greater has increased from approximately $12 \%$ to $79 \%$ between 1998 and 2008 .

In summary, we found Medicare THA patients with hard-on-hard (M-M, C-C) bearings had a similar risk of complications and revision THA compared to patients who had M-PE bearings during the first 2 years after primary THA. These findings provide a basis for additional analyses of the comparative effectiveness of THA bearing surfaces in the Medicare population.

Acknowledgments We thank Vanessa Chiu, MPH for her help in preparing this manuscript.

Open Access This article is distributed under the terms of the Creative Commons Attribution Noncommercial License which permits any noncommercial use, distribution, and reproduction in any medium, provided the original author(s) and source are credited.

\section{References}

1. Agency for Healthcare Research and Quality. HCUP Databases. Healthcare Cost and Utilization Project (HCUP). 2007. Available at: http://hcupnet.ahrq.gov/. Accessed January 9, 2009.

2. Australian Orthopaedic Association National Joint Replacement Registry Web site. Hip and Knee Arthroplasty. Annual Report 2009. Available at: http://www.dmac.adelaide.edu.au/aoanjrr/ publications.jsp. Accessed January 9, 2009.

3. Berger RA, Jacobs JJ, Quigley LR, Rosenberg AG, Galante JO. Primary cementless acetabular reconstruction in patients younger than 50 years old. 7- to 11-year results. Clin Orthop Relat Res. 1997;344:216-226.

4. Berry DJ, Harmsen WS, Cabanela ME, Morrey BF. Twenty-fiveyear survivorship of two thousand consecutive primary Charnley total hip replacements: factors affecting survivorship of acetabular and femoral components. J Bone Joint Surg Am. 2002;84: 171-177.

5. Berry DJ, von Knoch M, Schleck CD, Harmsen WS. The cumulative long-term risk of dislocation after primary Charnley total hip arthroplasty. J Bone Joint Surg Am. 2004;86:9-14.

6. Boardman DR, Middleton FR, Kavanagh TG. A benign psoas mass following metal-on-metal resurfacing of the hip. $J$ Bone Joint Surg Br. 2006;88:402-404.

7. Bozic KJ, Kurtz S, Lau E, Ong K, Chiu V, Vail TP, Rubash HE, Berry DJ. The epidemiology of bearing surface usage in total hip arthroplasty in the United States. J Bone Joint Surg Am. 2009;91: 1614-1620.

8. Bozic KJ, Kurtz SM, Lau E, Ong K, Vail TP, Berry DJ. The epidemiology of revision total hip arthroplasty in the United States. J Bone Joint Surg Am. 2009;91:128-133.

9. Clarke IC, Good V, Williams P, Schroeder D, Anissian L, Stark A, Oonishi H, Schuldies J, Gustafson G. Ultra-low wear rates for rigid-on-rigid bearings in total hip replacements. Proc Inst Mech Eng H. 2000;214:331-347.

10. Clarke IC, Gustafson A. Clinical and hip simulator comparisons of ceramic-on-polyethylene and metal-on-polyethylene wear. Clin Orthop Relat Res. 2000;379:34-40.

11. Clayton RA, Beggs I, Salter DM, Grant MH, Patton JT, Porter DE. Inflammatory pseudotumor associated with femoral nerve palsy following metal-on-metal resurfacing of the hip. A case report. J Bone Joint Surg Am. 2008;90:1988-1993.

12. Delaunay CP, Bonnomet F, Clavert P, Laffargue P, Migaud H. THA using metal-on-metal articulation in active patients younger than 50 years. Clin Orthop Relat Res. 2008;466:340-346.

13. Deyo RA, Cherkin DC, Ciol MA. Adapting a clinical comorbidity index for use with ICD-9-CM administrative databases. J Clin Epidemiol. 1992;45:613-619.

14. Eingartner C. Current trends in total hip arthroplasty. Ortop Traumatol Rehabil. 2007;9:8-14.

15. Fisher J, Jin Z, Tipper J, Stone M, Ingham E. Tribology of alternative bearings. Clin Orthop Relat Res. 2006;453:25-34.

16. Galvin A, Kang L, Tipper J, Stone M, Ingham E, Jin Z, Fisher J. Wear of crosslinked polyethylene under different tribological conditions. J Mater Sci Mater Med. 2006;17:235-243.

17. Heisel C, Silva M, Schmalzried TP. Bearing surface options for total hip replacement in young patients. Instr Course Lect. 2004; 53:49-65.

18. Kim YH, Oh SH, Kim JS. Primary total hip arthroplasty with a second-generation cementless total hip prosthesis in patients younger than fifty years of age. J Bone Joint Surg Am. 2003;85: $109-114$.

19. Korovessis P, Petsinis G, Repanti M, Repantis T. Metallosis after contemporary metal-on-metal total hip arthroplasty. Five to nineyear follow-up. J Bone Joint Surg Am. 2006;88:1183-1191.

20. Kurtz S, Ong K. Hard-on-hard bearings and highly crosslinked UHMWPE. In: Kurtz S, ed. The UHMWPE Biomaterials and Handbook: Ultra-High Molecular Weight Polyethylene in Total Joint Replacment and Medical Devices. Burlington, MA: Academic Press; 2009.

21. Mendenhall S. 2009 Hip and Knee Implant Review. Orthopedic Network News. July 2009. Available at: www.orthopedicnetwork news.com. Accessed January 9, 2009.

22. Mikhael MM, Hanssen AD, Sierra RJ. Failure of metal-on-metal total hip arthroplasty mimicking hip infection. A report of two cases. J Bone Joint Surg Am. 2009;91:443-446.

23. Milosev I, Trebse R, Kovac S, Cor A, Pisot V. Survivorship and retrieval analysis of Sikomet metal-on-metal total hip replacements at a mean of seven years. J Bone Joint Surg Am. 2006; 88:1173-1182.

24. Murray SB, Bates DW, Ngo L, Ufberg JW, Shapiro NI. Charlson Index is associated with one-year mortality in emergency department patients with suspected infection. Acad Emerg Med. 2006;13:530-536.

25. Ogino D, Kawaji H, Konttinen L, Lehto M, Rantanen $P$, Malmivaara A, Konttinen YT, Salo J. Total hip replacement in patients eighty years of age and older. J Bone Joint Surg Am. 2008;90:1884-1890.

26. Park YS, Moon YW, Lim SJ, Yang JM, Ahn G, Choi YL. Early osteolysis following second-generation metal-on-metal hip replacement. J Bone Joint Surg Am. 2005;87:1515-1521.

27. Schmalzried TP, Shepherd EF, Dorey FJ, Jackson WO, dela Rosa M, Fa'vae F, McKellop HA, McClung CD, Martell J, Moreland JR, Amstutz HC. The John Charnley Award. Wear is a function of use, not time. Clin Orthop Relat Res. 2000;381:36-46.

28. Sexton S, Steiger R, Jackson M. Bearing surface and risk of revision due to dislocation after primary total hip arthroplasty. Paper \#F584. Paper presented at: 10th EFORT Congress, 2009; Vienna. Available at: http://www.efort.org/cdrom2009/FreePaper Content.asp?Pid=F584. Accessed January 9, 2009.

29. Soderman P, Malchau H, Herberts $P$, Zugner R, Regner H, Garellick G. Outcome after total hip arthroplasty: Part II. Disease-specific follow-up and the Swedish National Total Hip Arthroplasty Register. Acta Orthop Scand. 2001;72:113-119. 